\title{
Using a Student Response System (Socrative) as a Pre- Reading Method in an EFL Reading Environment"
}

\author{
Cha, Yoonjung \\ (Hanshin University)
}

\begin{abstract}
Cha, Yoonjung. (2018). Using a student response system (Socrative) as a prereading method in an EFL reading environment. STEM Journal, 19(2), 95-119.

The purpose of this study is to explore whether a student response system (SRS), Socrative, can be effective in supporting students' reading comprehension when applied at the pre-reading phase. The purpose of utilizing Socrative was to enhance participation and promote collaboration among learners when they interact with one another in order to discuss their background knowledge of the reading passage. The 81 participants were comprised of undergraduate students from Gyeonggi province. They were assigned to two different groups, an experimental group using Socrative, and a control group without Socrative. The participants took the pre-test prior to performing the pre-reading activities. Then, both groups went through identical prereading activities with the exception being that one group used Socrative. After the pre-reading activities, a post-test was conducted in order to examine the learning gains. There was a significant difference found within the group using Socrative from the pre- to the post-tests; however, no significant difference was found between the two groups (Socrative versus non-Socrative). Participants' perspectives on using Socrative were reported using both questionnaires and interviews. Participants showed a positive attitude toward using Socrative for reading classes. Pedagogical implications and futures studies were suggested based on the findings of this study.
\end{abstract}

\section{INTRODUCTION}

Active participation from students is considered one of the essential ingredients for making language classrooms successful (Stowell \& Nelson, 2007). Instructors have frequently attempted to implement different methods to more deeply engage students in classroom activities. However, less challenging, shy, or demotivated learners may have difficulty participating even in small group sessions where such methods are used.

* This work was supported by a special research grant from Hanshin University. 
Moreover, even if learners are motivated and eager to participate, certain educational settings, such as large classes, can hinder learners from actively volunteering for the fear of making mistakes (Caldwell, 2007).

Agbatogun (2014) noted that "interaction is a key element to successful instructional processes" (p. 257). But how can we help learners become active participants in the classroom, especially in EFL language classes? Integrating mobile technology has proven to be a promising solution, given that many positive outcomes involving learners' active engagement have been reported in the literature (Cha \& Kim, 2016; Hsu, 2013; Kim, 2014; Kim, 2018; Praag \& Sanchez, 2015; Stockwell, 2010). Moreover, a particular technology known as the Student Response System (SRS) has been extensively accepted among educators for enhancing students' participation (Cardoso, 2011; Dakka, 2015; Hunsu, Adesope, \& Bayly, 2016; McDonough \& Foote, 2015; Yoon, 2017).

As modern technology develops over time, SRS has also evolved from using simple handheld devices to a system embedded in a mobile application format. One of the popular clicker applications is Socrative (2017), which is an Internet-based platform. This particular application offers some unique advantages over other types of SRSs. These days, many students carry smartphones. Therefore, the application is easily accessible as long as one has an internet connection because the program is freely available to anyone. Wash (2014) suggested that Socrative has "the most flexibility and ease of use" (p. 99) compared to other SRSs. Moreover, by using Socrative, instructors could generate quizzes instantly and make different types of exercises. It further allows immediate responses from students. Thus, instructors can provide feedback and monitor students' performance in real time. Furthermore, the results of the students' responses are organized in a report format (Awedh, Mueen, Zafar, \& Manzoor, 2014; Dakka, 2015; Kaya \& Balta, 2016).

SRSs also refer to different names such as audience response system (Stowell \& Nelson, 2007), classroom response system (Fies \& Marshall, 2006), learner response system (Lee \& Oh, 2014; Yoon, 2017), and clickers (Chien, Chang, \& Chang, 2016; McDonough \& Foote, 2015). The aforementioned studies adopted SRSs for the following reasons: (a) to increase students' engagement, (b) to improve interaction, (c) to motivate students to stay interested in the learning process, (d) to encourage peer discussions, and (e) to enhance learning outcomes.

SRSs, according to Hung (2017), is "an integrated technology solution that has been used to create interactive classrooms in higher education" (p. 17). In this regard, many educators use the SRS in different fields such as science methods courses for education majors (Wash, 2014), engineering (Dakka, 2015), psychology (Stowell \& Nelson, 2007), computer architecture (Awedh et al., 2014), history/social studies (Waters, Kenna, \& Bruce, 2016), economics (Green, 2016), and English (Hung, 2017; Lee \& Oh, 2014; McDonough \& Foote, 2015). Regarding English related studies, some of them use an SRS, 
but in a different context such as implementing it in a flipped classroom (Hung, 2017); while others focused on collaborative learning for English grammar quizzes (McDonough \& Foote, 2015), active learning for reading (Lee \& Oh, 2014; Shaban, 2017), and/or communicative approaches (Cardoso, 2011). The positive results of using SRSs including Socrative were evident among the aforementioned studies but some of the results were based on survey studies, rather than on the actual achievement scores of the students. In addition, some studies revealed inconclusive results of using an SRS. That is, in some studies, those who did not use SRSs scored higher on their performance outcomes (Lin, Liu, \& Chu, 2011; Patterson, Kilpatrick, \& Woebkenberg, 2010).

As a result, few empirical studies have investigated the use of SRSs in terms of EFL reading classes for participants' academic performance, especially in English reading comprehension. Thus, instead of employing an SRS in the whole reading process (pre, while and post), this study intended to focus on the pre-reading phase adopting pre-reading activities such as activating background knowledge using previewing questions. In order to build better comprehension, understanding and activating background knowledge are important (Grabe, 2009). Chen and Graves' (1995) findings that previewing and presenting background knowledge improved reading comprehension have been confirmed by many subsequent studies (Alemi \& Ebadi, 2010; Han \& Im, 2010; Moghaddam \& Mahmoudi, 2016). Since pre-reading activities can incorporate considerable engagement from participants for discussions and answering previewing questions, an SRS could play an important role especially for those who lack active participation skills due to shyness or anxiety (Kaya \& Balta, 2016). In other words, the advantages of using an SRS could be beneficial for students to become more involved in the active learning process for the prereading stage. In any case, if an SRS is used for every reading process, from pre-to postreading, it might be difficult to track the actual effects of the SRS and identify the role of the SRS for improving reading comprehension.

Therefore, the aim of this research was to shed light on the effects and implications of using a student response system, Socrative, a mobile application, particularly in the prereading stage for EFL reading classes. More specifically, it was to explore whether or not using this SRS application in the pre-reading stage can assist in enhancing undergraduate students' reading comprehension and their perspectives on using SRSs. With regard to the first research question, the study investigated the differences of the mean scores between the pre- and post-tests. This was to verify whether Socrative can be an effective educational tool particularly in the pre-reading phase of the reading process. As for the second research question, students' learning experience using Socrative was analyzed in terms of strengths, limitations, and suggestions for the better use of SRS in the future.

The research questions are as follows:

1. Is using the SRS in the pre-reading phase effective for reading comprehension among 
EFL undergraduate students?

2. What are the undergraduate students' perspectives on using the SRS in the prereading phase in EFL reading classes?

\section{LITERATURE REVIEW}

\section{Mobile-Based Language Learning}

Mobile-based language learning has become a well-established approach in foreign language classrooms. Many advantages of using such technology are discussed by Richards (2015): “a) It can access more engaging materials, b) It can encourage more active learning, c) It can provide a stress-reduced environment, d) It can encourage learner autonomy, and e) It can increase motivation" (p. 642). These benefits are re-affirmed in many mobile-related language learning studies (Berry, 2015; Cha \& Kim, 2016; Kim, 2014; Kim, Rueckert, Kim, \& Seo, 2013; O, 2015; Wang \& Smith, 2013).

Despite the well-known advantages of mobile-based language learning, KukulsaHulme (as cited in Pegrum, 2014) expressed two contrarian views. One of them was to claim that the difference in language learning is rather just in the medium, a helpful technological resource, and not in the learning content itself. She curiously noted that useful tools "have no real impact on learners' practice" (Pegrum, 2014, p. 22). On the contrary, she explained that mobile learning has changed language learners' method of learning in various ways such as introducing different ways of communicating with others, and using educational tools to record and analyze language data. Moreover, mobile technology has provided more opportunities for accessing education both locally and internationally.

With regard to learning content in mobile-based language learning, technological tools such as mobile applications may or may not have a great influence on learning outcomes of the students even though participants' perceptions of using mobile applications have been reported as positive (Kim, 2014; Kim \& Park, 2015). Moreover, many empirical studies firmly support mobile-based language learning as mentioned above. As such, a different methodological approach to mobile-based language learning could be a key to successful language learning classroom.

The SAMR (Substitution, Augmentation, Modification, and Redefinition) model which was introduced by Puentedura (2014) can be adopted in technology-enhanced language classrooms especially using different types of mobile applications. The first stage is Substitution, which is substituting a mobile tool without any expectations of learning gains (Jang \& Kim, 2015). The next stage is Augmentation, that is, using a particular mobile 
technology with gains in learning improvement (Jin, 2014; Kim, 2014; Moon \& Kim, 2011; $\mathrm{O}, 2015)$. These studies used mobile-based language learning to develop various skills such as listening, reading, and writing. They reported improved learning gains using mobiles with given tasks such as language-related activities (grammar, listening exercises, writing activities), topic-related discussions, and quizzes. Participants were mostly undergraduate students whose perspectives were evidently optimistic towards employing mobile-based learning, especially in the language learning classroom. The last two stages of SAMR are Modification, which refers to redesigning tasks (Kim \& Park, 2015; Liu, 2016), and Redefinition, which pertains to making new tasks.

In light of language-based mobile learning, the substitution and augmentation phases can be broadly applied; however, based on how these tasks are designed or modified by instructors or participants themselves, participants can go beyond those two initial stages (substitution and augmentation). While the SAMR model is not directly stated and applied in many of the empirical studies on mobile-based language learning, it could certainly be employed in mobile-based language learning classrooms. With regard to the present study, it was used to investigate the efficiency of using the SRS in terms of reading comprehension. Thus, in the second stage, augmentation has been used in this case.

\section{Student Response System (SRS)}

The potential benefits of SRSs have been noted in the previous literature in terms of the general academic environment (Penuel, Boscardin, Masyn, \& Crawford, 2007; Stowell \& Nelson, 2007; Wang, 2015) as well as in ESL/EFL English classes (Cardoso, 2011; McDonough \& Foote, 2015). The reasons for using SRSs frequently coincide with the advantages of using SRSs in classes. Kay and LeSage (2009) reviewed 67 studies and summarized the benefits of an SRS (classroom environment benefits, learning benefits, and assessment benefits) as well as the challenges accompanying its use (technological challenges, teacher-based challenges, and student-based challenges).

For the academic environment, Wang (2015) implemented a game-based SRS called Kahoot. This study compared the use of this SRS for one single lecture compared with using it for every lecture for five consecutive months in terms of classroom dynamics, student engagement, motivation, perceived learning and frequency of usage. The findings suggested that classroom dynamics greatly improved. Regarding student engagement and motivation, there were no statistical differences, but $90 \%$ of the participants stated that they were both engaged in quiz sessions and motivated to play games during the lecture. $75 \%$ of the participants acknowledged that they learned something from using Kahoot. Lastly, most of the participants wanted to use it again in different lectures (Chien et al., 2016). In short, using game-based SRSs could benefit students as long as they are provided 
with different variations in the game modes.

In regard to using a learner response system (LRS) in an English learning environment, Cardoso (2011) conducted questionnaires and interviews to investigate students' perceptions on an LRS in English classes. It can be concluded that students positively favored using an LRS. The results indicated that the LRS "a) increased motivation and students' participation in the class, b) promoted self-assessment, c) allowed them to compare themselves with their peers, and d) more importantly, contributed to learning" ( $p$. 409). McDonough and Foote (2015), for their part, focused on the effects of individual or shared use of clickers in English grammar class. The results demonstrated that students were more involved in interacting with peers when sharing the clickers. Moreover, sharing the clickers with others led to providing more accurate answers. Students also expressed the importance of collaborative reasoning with a partner through clickers' activities.

In a different methodological learning context, Hung (2017) used an SRS in flipped classrooms to explore whether students were actively involved in the language learning experience. These findings suggested that students were satisfied with this approach Furthermore, using SRSs in language classrooms proved to be beneficial in terms of experiencing collaborative learning opportunities.

Some studies explored how SRSs can be positively utilized in EFL language classes. Lee and Oh (2014) investigated how LRSs influenced students' learning outcomes in reading classes. The students were divided into two different groups: an experimental group using the clicker and a control group without any clicker use. A clicker used in the study was called Quiz Bell. They took a diagnostic reading test, a mid-term exam, and a final exam. The results revealed that a statistical improvement was found both in the midterm and the final exam, which implied that LRSs can be a useful tool in enhancing the academic performance of the students.

These following research studies focused on using Socrative as an SRS. Kim and Hur (2016) compared three different mobile applications (NAVER band, Socrative, and Kakao Talk) in English classes. The results revealed that all three mobile applications proved to be positive in terms of participants' satisfaction and interests. Moreover, regarding the academic achievement, there were no statistical differences among the three different mobile applications, but a statistical difference was found within each mobile application. Furthermore, for the affective domains, Socrative received the highest mean scores.

Yoon (2017) examined participants' perceptions on using Socrative in EFL classrooms. Pre- and post-surveys focused on the effects of various types of activities provided by the Socrative application. At the beginning of the class, participants were not too keen on learning English, but using Socrative became a catalyst for higher participation in the four language skills-based activities. The results revealed that participants' active engagement in the activities was a function of the anonymity of the application, which led to promoting 
more interaction among them

Additionally, Shaban (2017) implemented Socrative in English reading classes for undergraduate, international students who were learning English as a second language, reporting that Socrative helped students to actively participate in discussions without the fear of being exposed to others even when they were wrong. Moreover, one of the shy Asian students was encouraged to speak in front of others with the help of Socrative. Comments from students who used Socrative in their classes were positive, and they were supportive of this active learning experience. Kaya and Balta (2016) explored the use of Socrative for undergraduate students. They conducted a survey after using Socrative in English classes for grammar quizzes and discussions. The results revealed that $86 \%$ of the students stated that Socrative was helpful in learning English and $74 \%$ of them replied that it helped them to engage more in activities.

On the whole, the aforementioned studies confirmed the positive aspects of using SRSs or Socrative in English classes; however, there were hardly any studies involving academic performance on reading comprehension using an SRS. More studies are necessary to examine the academic effects for EFL students, especially in reading comprehension using a mobile application of an SRS. Therefore, this study intends to illustrate whether the SRS, Socrative, can be a practical, and efficient tool in a language learning environment.

\section{METHODOLOGY}

\section{Participants}

The participants of this study were 81 undergraduate students from Gyeonggi province. They were required to take a general English course. Students majoring in Applied Statistics and Global Business participated in this research. There were 41 Statistics' students (19 females and 22 males) comprising one group, and all of them were freshmen except for one student who was a sophomore retaking this course. Only one student had experience with living abroad when he was in middle school for three years. As for the Global Business students, there were 40 freshman students (26 females and 14 males) registered for this English course. None of the students had any experience of living in English speaking countries.

These two classes were assigned to two different groups: an experimental (Socrative) group versus a control (non-Socrative) group. Participants majoring in Applied Statistics used Socrative, as a learning tool in the pre-reading phase for their reading classes while those who majored in Global Business carried out the pre-reading activities without any 
mobile technology. They only used a textbook and other printed hand-outs. In other words, both groups carried out the same pre-reading activities with or without Socrative, a mobile learning tool.

At the beginning of the semester, the participants took a pre-test in order to investigate whether the participants in these two classes had any differences in reading proficiency. The result revealed that both classes were statistically homogeneous ( $\mathrm{Sig} .=.12, p>.05$ ). In other words, there were no significant differences between these two classes.

\section{Teaching Procedures and Data Collection Instruments}

The main skill focus of the general English classes was reading. These two classes were provided with an opportunity to go through the pre-reading, while-reading, and postreading stages. As for this particular study, a different treatment was implemented only in the pre-reading stage. Due to the fact that this study specifically centered on the efficiency of using Socrative in the pre-reading stage, the experiment was conducted at the beginning of the semester for the first reading chapter. The whole process took two weeks including taking the pre- and post-tests, doing the pre-reading activities, and filling out the questionnaires. Interviews were administered at the end of the semester.

The two classes were taught with the same textbook, Reading Explorer 3 (Douglas \& Bohlke, 2015). The first reading, Skin: The Body's Canvas, was selected for several prereading activities which included previewing questions and predicting the main reading passage. Regarding the traditional group (non-Socrative goup), titles and subtitles were shown using a power point presentation where the instructor tried to encourage students to predict the main reading passage by way of a whole-class discussion. The main reading passage included several types of tattooing; therefore, pictures were used to elicit background knowledge and the participants' experiences of tattooing were discussed. Next, the instructor provided a printed hand-out of ten previewing statements which were carefully selected from the main reading passage. Then, students were asked to check each statement as to whether it was true or false. After they were finished, the instructor and students checked the correct answers one by one and discussed the statements which could lead them to understand the main reading passage.

The experimental group, on the other hand, used Socrative to support and elicit more participation from students to boost students' interest and engage in more active discussion (Lee \& Oh, 2014; Yoon, 2017) for the pre-reading activity. Socrative is a mobile application and one of the learning tools which can be used for elevating active participation from the students (Kim \& Hur, 2016; Yoon, 2017). This application has both a mobile and $\mathrm{PC}$ version, that features both a teacher version and a student version. For this study, a free version was used. 
The same pre-reading procedure was thus applied to both groups. The main difference was whether or not using the Socrative in the pre-reading stage. In other words, the goal was to verify whether there was a distinctive difference in pre-reading stage results using the mobile application on the one hand, versus using a traditional textbook and handouts, on the other.

When the instructor logged into the Socrative application, a room for real-time interaction was automatically created. The main menu includes a Quick Question section that has Multiple Choice (MC), True/False (TF), and Short Answer (SA) options. As for this study, TF and SAs were used for the pre-reading stage. For MC and TF, the instructor had to make the questions in advance in order to save time. One of the greatest benefits of using MC and TF was that it could demonstrate students' responses in percentage forms. Students could immediately find out whether their responses were correct or incorrect in real time. That is, they received instant feedback. Particularly for MC questions, even though the answer was obvious to some, it was not so easy for all students to choose the correct answer. It would be quite interesting to understand why students chose the answers they did, even the wrong ones. This could lead instructors not to fall into the assumption that all students will get the correct answer when a question appears easy. If MC and TF questions were done in a paper or a textbook, it would be very difficult to find out what kind of responses every student chose all at once. Additionally, for students, they might feel relieved that they were not the only ones who did not get the correct answer because they can check everyone else's responses simultaneously. Regarding SA questions, it would be helpful to read all the responses at once when participants are discussing the background knowledge of the reading passage. As soon as students wrote their responses to the questions the instructor posed, they were instantly shown on the screen. Reading others' opinions could help students reflect on their own responses and an instructor could get different kinds of responses from all students.

Another valuable feature offered by Socrative is anonymity (Agbatogun, 2014; Kaya \& Balta, 2016; Yoon, 2017), which encouraged every student to type in their opinions without fear of being embarrassed by a wrong answer. In this way, the participants did not have to be afraid of being standouts among other students. All of the participants could read their friends' comments about the questions without knowing the identity of the commenters. On the computer screen, some students' responses were in English while others answered in Korean. Students could respond in any language they prefer. Writing responses in English was not mandatory. The instructors made it optional for the participants.

At the beginning of the semester, the participants took the pre-test. It was comprised of 20 comprehension questions from the first reading of the textbook mentioned above. The main reading passage was divided into three sections. Each section included six to seven 
different types of questions: multiple choices, true/false, and short answers. Questions also consisted of asking for main ideas, purposes, referent words, inferences and details. After the pre-test, each group, the control (non-Socrative) group and the experimental group (Socrative) performed pre-reading activities as described above. Then, students took the same test as the post-test to explore whether using Socrative was effective as a means to help them understand the main text.

Moreover, a questionnaire was conducted in order to examine students' perspectives and experience using Socrative as a pre-reading activity. Three open-ended and twelve close-ended items were administered. As for the close-ended statements, all the items were organized using the 6-point Likert-type scoring matrix (6=strongly agree, 5=agree, $4=$ slightly agree, $3=$ slightly disagree, $2=$ disagree, $1=$ strongly disagree). The items in the survey questionnaires were presented in Korean for better understanding (Cardoso, 2011). Later, in the study, all of the items were translated and reported in English. Finally, for the interview, six students (three male and three female) were randomly chosen from the Socrative class and each of them took approximately half an hour to 40 minutes to talk about using Socrative in the pre-reading stage. Again, every interview was conducted in Korean. They were transcribed and translated into English for the purpose of this study.

\section{Analysis}

The data yielded here was comprised of pre- and post-tests, questionnaires, and interviews. Descriptive data was analyzed in SPSS 17.0. In order to compare the mean scores within each group, the Socrative group and non-Socrative group, paired sample $t$ tests were employed. To examine whether Socrative can be a statistically effective mobile tool compared to traditional methods, an independent $t$-test was performed. Furthermore, to investigate how Socrative can be meaningful and efficient in reading classes, an independent $t$-test was employed to report the means of closed-ended and open-ended statements on the questionnaire. Finally, interviews were analyzed to explore the participants' perspectives on using Socrative in the reading classes. The reliability of the survey items were a Cronbach's alpha value of .923 .

\section{RESULTS AND DISCUSSION}

\section{Effects of SRS on Reading Comprehension}

In order to investigate the effects of the SRS, Socrative, in a pre-reading phase in EFL reading classes, the pre- and post-tests were carried out in a non-Socrative group $(N=40)$ 
and in a Socrative group $(N=41)$. The first research question was whether or not each different mode, the Socrative and non-Socrative, was effective in improving reading comprehension scores within groups. Pre- and post-test scores were analyzed to verify the differences before and after the treatment, and paired sample $t$-tests were performed.

As demonstrated in $\langle$ Table $1>$, the results of the paired sample $t$-test of the Socrative group (an experimental group) revealed that the mean scores of the pre-test were 13.17 $(S D=3.74)$ while the post-test scores netted $14.02(S D=3.41)$. The total score of both the pre- and post-tests was twenty points each. There was a significant difference between the two test scores $\left(t=-2.31, p=.026^{*}\right)$. The results indicate that using Socrative in the prereading phase was statistically effective in enhancing reading comprehension. It could be cautiously assumed that the pre-reading activities using Socrative may have played a supportive role in improving learning gains, a finding that is supported by Lee and $\mathrm{Oh}$ (2014). It would be difficult to point out exactly which factor actually led students to improve their reading comprehension scores, but it can be hypothesized that sharing their opinions about the previewing questions, and interacting with one another may have facilitated a better understanding of the reading passage (Shaban, 2017; Yoon, 2017). Dakka (2015) also corroborated this by noting that the participants performed better with the use of Socrative although the study was conducted in a different field.

TABLE 1

Results of Paired Sample $T$-Tests

\begin{tabular}{|c|c|c|c|c|c|}
\hline Test & Group & $M$ & $S D$ & $t$ & $p$ \\
\hline \multirow[t]{2}{*}{ Socrative group } & Pre-test & 13.17 & 3.74 & \multirow{2}{*}{-2.31} & \multirow{2}{*}{.026} \\
\hline & Post-test & 14.02 & 3.41 & & \\
\hline \multirow[t]{2}{*}{ Non-Socrative group } & Pre-test & 14.38 & 3.04 & \multirow{2}{*}{-1.78} & \multirow{2}{*}{.084} \\
\hline & Post-test & 15.03 & 2.94 & & \\
\hline
\end{tabular}

$* p<.05$

As for the non-Socrative group (the control group), they scored $14.38(S D=3.04)$ in the pre-test while they gained $15.03(S D=2.94)$ in the post-test. Instead of using Socrative in the reading process, this group performed the pre-reading activities using a traditional method like class discussions and handouts. Unlike the Socrative group, no significant difference was found between the two scores. It is, however, noteworthy that while there was a class discussion period for the non-Socrative group, participation from students was not as efficient as the Socrative group because it was not easy to draw their opinions voluntarily. Many students kept their opinions about the content to themselves, which might have generated similar results for the post-test. Chien, et al. (2016) suggested that in order to have positive learning outcomes for clicker-integrated instruction, discussion about the given questions was highly recommended. 
To investigate the effects of using Socrative in a pre-reading phase between the two groups, independent sample $t$-tests were conducted. The differences between the pre- and post-tests of reading comprehension were analyzed. The findings are illustrated in $<$ Table $2>$.

TABLE 2

Results of Independent Sample $T$-Test

\begin{tabular}{cccccc}
\hline \hline Test & Group & $M$ & $S D$ & $t$ & $p$ \\
\hline Pre-test & Socrative Group & 13.17 & 3.74 & \multirow{2}{*}{-1.59} & .12 \\
& Non-Socrative Group & 14.38 & 3.04 & & \\
Post-test & Socrative Group & 14.02 & 3.41 & -1.41 & .16 \\
& Non-Socrative Group & 15.03 & 2.94 & \\
\hline
\end{tabular}

${ }^{*} p<.05$

Regarding the pre-test, the Socrative group scored $13.17(S D=3.74)$ while the NonSocrative group scored $14.38(S D=3.04)$. No significant difference was found in the pretest scores between the two groups $(t=-1.59, p=.12)$. That means that both groups were homogeneous, as mentioned previously. Similarly, the mean score of the Socrative group was $14.02(S D=3.41)$ while that of the Non-Socrative group was $15.03(S D=2.94)$ in the post-test. Again, there was no significant difference between the two groups $(t=-1.41, p$ $=.16$ ). In short, statistically speaking, when comparing the Socrative and non-Socrative groups, using the Socrative application may not have been a critical factor in the reading comprehension scores. However, the mean scores of the post-tests for both groups slightly improved.

This may be due to the fact that there might not have been enough time to employ various pre-reading activities using Socrative. Alemi and Ebadi (2010) argued that applying appropriate pre-reading activities such as vocabulary-related exercises could be beneficial in improving reading comprehension scores. Moreover, it could be attributed to the fact that using Socrative in the pre-reading stage to understand the whole passage may have been demanding for some participants who were less interested in learning English than others. The present study also examined whether or not SRSs can further incentivize classroom interaction, specifically for the pre-reading stage in order to enhance reading comprehension, and not for the whole reading process. Hardly any studies have explored the comparative research for improving reading comprehension just by using SRSs. Thus, it would be challenging for this study to corroborating the results of others.

\section{Participants' Perspectives Towards the Student Response System}

\section{1) Participants' Perspectives on Using Socrative in the Pre-Reading Stage}


To explore the results of the second research question, the participants' perspectives on using Socrative in the pre-reading phase, a questionnaire including both close-ended and open-ended questions, as well as interviews, were administered. Due to the scope of the study, only the results from the Socrative group were collected. There were 12 items in the questionnaire which were developed based on the students' overall behaviors and attitudes employing Socrative in the pre-reading stage for EFL reading classes. The survey results were divided into two sections: attitudes (items 1-6) and pre-reading related statements (items 7-12). Participants responded to each item from 1 (least agreeable) to 6 (most agreeable). This questionnaire was modified from the survey used in a different study (Kim \& Cha, 2017).

TABLE 3

Results of Survey: Students' Attitudes on Socrative

\begin{tabular}{|c|c|c|c|}
\hline & Attitudes: Items (\#1-6) & $M$ & $S D$ \\
\hline 1 & Using Socrative in the pre-reading stage was interesting. & 5.41 & .64 \\
\hline 2 & $\begin{array}{l}\text { Using Socrative in the pre-reading stage was motivating to read the } \\
\text { main passage. }\end{array}$ & 4.62 & .96 \\
\hline 3 & $\begin{array}{l}\text { Using Socrative in the pre-reading stage helped us relieve boredom } \\
\text { when reading the main passage. }\end{array}$ & 5.05 & .86 \\
\hline 4 & $\begin{array}{l}\text { Using Socrative in the pre-reading stage was helpful in gaining } \\
\text { confidence when reading the main passage. }\end{array}$ & 4.15 & .96 \\
\hline 5 & $\begin{array}{l}\text { Using Socrative in the pre-reading stage helped me to participate } \\
\text { actively in the class. }\end{array}$ & 4.95 & .89 \\
\hline 6 & $\begin{array}{l}\text { Using Socrative in the pre-reading stage to suggest my opinions felt } \\
\text { more comfortable than discussing in groups or pairs. }\end{array}$ & 4.92 & 1.04 \\
\hline
\end{tabular}

As can be seen in $\langle$ Table $3>$, items 1 to 6 presented participants' attitudes toward using Socrative in the pre-reading stage. The highest mean score was item 1, $5.41(S D=.64)$, Using Socrative in the pre-reading stage was interesting. This may be attributed to the fact that it was the participants' first time using Socrative, especially in the pre-reading stage for a reading class (Cardoso, 2011; Dakka, 2015; Shaban, 2017; Wang, 2015; Yoon, 2017). The second highest mean score was $5.05(S D=.86)$ for item 3, Using Socrative in the pre-reading stage helped us relieve boredom when reading the main passage. Since many students found Socrative interesting (item 1), it could be motivating for them to use the SRS when they were ready to learn the main passage as indicated in item $2(M=4.62$, $S D=.96)$

Particularly, item 5 Using Socrative in the pre-reading stage helped me to participate actively in the class was $4.95(S D=.89)$ and it was one of the essential points for using an SRS in many of the previous studies (Awedh et al., 2014; Chien et al., 2016; Dakka, 2015; 
Kaya \& Balta, 2016; Stowell \& Nelson, 2007; Yoon, 2017) which confirm the findings of the current study. For item 6, Using Socrative in the pre-reading stage to suggest my opinions felt more comfortable than discussing in groups or pairs implied that students preferred anonymity when voicing their opinions in front of others, which corroborated Shaban (2017) and Yoon (2017). Anonymity when expressing opinions was a key benefit of using this application.

$<$ Table $4>$ demonstrated the survey results for items 7 to 12 regarding the pre-reading related statements. The mean scores of Items 7 through 9 were 4.92, 4.56, and 4.90 respectively, and they were mostly related to the pre-reading strategies. It could be assumed that the participants found Socrative quite productive when understanding the main passage. However, compared to other items, item 10, Using Socrative in the prereading stage was helpful in improving reading skills, gained the lowest mean score ( $M=$ $3.87, S D=1.22$ ). This perhaps implies that students thought using Socrative may not enhance reading skills in that they only focused on pre-reading skills for this particular study. Improving reading skills would involve many different criteria including prereading skills and it is apparently not an easy task to accomplish in a short period of time.

TABLE 4

Results of Survey: Students' Perspectives on Socrative

\begin{tabular}{|c|c|c|c|}
\hline & Pre-Reading Related: Items (\#7-12) & $M$ & $S D$ \\
\hline 7 & $\begin{array}{l}\text { Using Socrative in the pre-reading stage helped us grasp the } \\
\text { background knowledge of the main passage. }\end{array}$ & 4.92 & .81 \\
\hline 8 & Using Socrative in the pre-reading stage was helpful for & 4.56 & .94 \\
\hline 9 & $\begin{array}{l}\text { Using Socrative in the pre-reading stage to discuss the title, and } \\
\text { subtitles helped us understand the gist of the main passage. }\end{array}$ & 4.90 & .72 \\
\hline 10 & $\begin{array}{l}\text { Using Socrative in the pre-reading stage was helpful in } \\
\text { improving reading skills. }\end{array}$ & 3.87 & 1.22 \\
\hline 11 & Using Socrative in the pre-reading stage was necessary. & 4.72 & .92 \\
\hline 12 & $\begin{array}{l}\text { Using Socrative in the pre-reading stage to view other students' } \\
\text { opinions was helpful in comprehending the main passage. }\end{array}$ & 4.97 & .84 \\
\hline
\end{tabular}

Noticeably, item 11 queried the necessity of using Socrative in the pre-reading stage. The mean score was $4.72(S D=.92)$. This could reflect the participants' active involvement in the process. In other words, Socrative could make every student participate in the pre-reading process in order to lead them to their final goal: understanding of the whole passage. The last item, item 12 , gained the highest score $(M=4.97, S D=.84)$ as demonstrated in $<$ Table $4>$. Many studies reported that viewing others' opinion could stimulate a better learning experience (Awedh et al., 2014; Green, 2016; Shaban, 2017; Yoon, 2017).

Consequently, the mean scores of 11 items except for item 10 indicated that students 
generally favored using Socrative in the pre-reading stage. These findings established that using Socrative in the pre-reading stage was conducive to understanding the main passage. Some items were closely related to useful pre-reading strategies; therefore, it can be cautiously assumed that employing these strategies in Socrative might have been an effective teaching method for this particular group of participants. Overall, students' perspectives on utilizing Socrative in the pre-reading stage were notably applicable and accommodating.

\section{2) Strengths, Limitations and Suggestions of Using Socrative}

Participants were guided to respond to three open-ended questions: strengths, limitations, and suggestions for using Socrative. The responses were analyzed by the researcher. Additionally, an interview was administered in order to closely examine students' perspectives about using Socrative in a reading class. Six students were selected for the interview: three male and three female students. They were all from the same group who used Socrative in the pre-reading stage. Interviews took 30 to 40 minutes through SNS. Those who agreed to participate in the interviews were able to read the content of the interview, and its content in Korean was translated by the researcher in English.

As for the first question in the open-ended questionnaire, students were asked to address the advantages of employing Socrative in the pre-reading stage for reading classes. Their responses are demonstrated in $\langle$ Table $5>$. Some students stated several advantages which were counted separately.

TABLE 5

\begin{tabular}{lc}
\multicolumn{2}{c}{ Advantages of Socrative } \\
\hline \hline
\end{tabular}

16 students stated that "it was useful when trying to grasp the gist of the reading passage." This was one of the main pre-reading strategies and students believed that 
Socrative can be a desirable teaching method for understanding the gist of the reading. As mentioned previously in the closed-ended questionnaire section, 10 students reported that it was interesting to "view others' opinions" which was considered one of the benefits of using a SRS. More students mentioned that using Socrative was "interesting" and that, "due to its anonymity, they could confidently express their opinions," that "it was easy to understand the main passage," and others.

Regarding the advantages, some of the excerpts were from interviewees' comments which overlapped with the advantages all of the students mentioned in $\langle$ Table $5>$. Surprisingly, 'anonymity' was addressed as the central point among interviewees (see excerpts S1, S2, and S3). For this particular Socrative group, more than 40 students were in a class. It might be difficult for some of them to discuss their own opinions in front of others for fear of making mistakes, or just being conscious of others' approval (Stowell \& Nelson, 2007). Thus, the 'anonymity' can be one way to relieve the pressure of being acknowledged by others (Shaban, 2017; Stav, Nielsen, Hansen-Nygard, \& Thorseth, 2010).

(1) S1 (female): Since using Socrative was anonymous, some shy students who do not have the courage to speak out could confidently voice their opinions. Also, I may get a chance to find out what I didn't know about certain parts of the reading from others' opinions.

(2) S2 (female): Definitely, the anonymity. This way, I can express my opinions comfortably and also look at others' point of view.

(3) S3 (male): One of the advantages is unquestionably anonymity. Students do not feel the pressure of talking about their thoughts.

(4) S4 (female): Using Socrative, just by looking at the topic, I can draw out some context behind it. I can also see other's ideas. It created a positive impact on participation.

(5) S5 (male): At the beginning of the semester, it was a great way to share friends' ideas. Also, since many friends sent their thoughts instantaneously, I could read them all at once. I could get lots of information to help figure out the main passage. In other words, it was very helpful because Socrative can convey so much information so quickly.

(6) S6 (male): It can be best used for understanding the topic of the reading passage. In a way, I could learn unknown vocabulary as well by reading others' written opinions.

The second question was about the disadvantages of using Socrative in the pre-reading stage for reading classes. Various responses were elicited and presented in $<$ Table $6>.27$ 
students stated that "Class atmosphere could become distracted because of unnecessary comments." Because of anonymity, students occasionally posted unrelated commentary. Because there was no way of finding out who wrote what, students could be distracted by those comments which were sometimes funny, but out of context. To avoid making these comments, a teacher could make students write their real names right after they logged into the application. Also, if making relevant comments are linked to grades, their attitudes would likely change.

TABLE 6

Disadvantages of Socrative

\begin{tabular}{lc}
\hline \hline \multicolumn{1}{c}{ Responses } & Number of Responses \\
\hline $\begin{array}{l}\text { Class atmosphere could become distracted because of unnecessary } \\
\text { comments. }\end{array}$ & 27 \\
$\begin{array}{l}\text { Activity can be delayed because some students posted their opinions } \\
\text { slowly. }\end{array}$ & 2 \\
Using Korean & 1 \\
Technicality (data use) & 1 \\
\hline
\end{tabular}

Disadvantages reported by interviewees are illustrated below. However, their opinions were similar to the comments in $\langle$ Table $6>$. Regarding excerpt (11), diversity can be one of the positive points for an SRS so it could be important to consider question types when posing questions to students. When asking about some of the meanings from a reading passage, it is likely that similar answers could come up.

(7) S1: I don't particularly see any negative points of using Socrative, but sometimes some students did not concentrate, and instead of posting their opinions through Socrative, they just played with their smartphones.

(8) S2: Well, I can't think of one. Maybe students posted unnecessary remarks.

(9) S3: It took too much time. Every student had to login and after they finished writing their thoughts, they had to wait for everyone to finish.

(10) S4: I felt uncomfortable when some students talked nonsense while we were doing Socrative and discussing learning materials.

(11) S5: When we responded to talk about experiences, it was great to see various comments, but when asking about some meanings of the passage, friends' answers were similar so there weren't many different answers.

(12) S6: Due to anonymity, some of them made jokes which influenced the atmosphere of the whole class.

The last question, suggestions for using Socrative, are as follows. Not many students 
suggested how to implement Socrative in a reading class. One of the new ideas was using English instead of Korean. For this particular study, Korean was used in order to encourage more ideas from students since it was the first time they used the application. Also, one student suggested not limiting the responses. The reason they were limited was because it would be difficult to know whether everyone in the class had responded to the posed question. Several students could provide many answers, but some may not even bother to answer. However, unlimited responses could make students more engaged in a discussion.

With respect to the opinions of interviewees, all of them would like to try this application again next semester. They thought using Socrative was quite effective when used in the pre-reading stage. Some of the suggestions they provided were extremely applicable. These suggestions should be applied not only for pre-reading, but for whole reading classes.

(13) S1: How about a one-sentence summary for those who didn't fully understand the passage?

(14) S2: For reading comprehension, each group can provide a summary for each assigned paragraph and then students can compare their answers with other group members through Socrative. Also, we can talk about the topic of each paragraph and a key sentence in each paragraph.

(15) S3: The instructor could pick out the important or difficult sentences. Then, students can discuss those sentences either by groups or individually.

(16) S4: We can summarize each paragraph and compare them with the main idea in order to figure out how main ideas can be linked to each summary.

(17) S5: We can talk about the meanings without using Socrative, and then discuss how those meanings can be related to students' personal experience or how they feel using Socrative.

(18) S6: We can discuss the topic and pick out some important details. The instructor can make the questions out of those details so that students could use Socrative to share and solve comprehensive questions.

As demonstrated in excerpts from (13) to (18), students provided valuable suggestions for future reading classes using Socrative. This study put an emphasis on the pre-reading stage, but with those recommendations, Socrative can be incorporated in more effective ways for language learners in reading classes as a whole. In short, the interviewee's insightful viewpoints about the strengths of SRSs are consistent with other studies. (Agbatogun, 2014; Green, 2016; Hunsu et al., 2016; Kaya \& Balta, 2016; Lee \& Oh, 2014; Wash, 2014). It also should be noted that instructors should find a way to control operating 
confines of Socrative, especially in terms of students making unnecessary jokes. Consequently, using Socrative was perceived to be fun, engaging, and proved to be a satisfying learning experience for students.

\section{CONCLUSION AND IMPLICATIONS}

This study aims to examine whether a student response system (SRS) can be an effective method in the pre-reading stages and how students perceived the use of Socrative in reading classes. The findings of this study suggest a few pedagogical implications in the EFL reading classes. The summary of the results are also elucidated along with related pedagogical implications.

First, this study was the first attempt to use a SRS, Socrative, in a pre-reading stage for EFL reading classes. The results on the academic performance was not statistically confirmed between the Socrative group and non-Socrative group in the postcomprehension test, but significant difference was found within the Socrative group. That is, there was a statistical increase from the pre-test to the post-test in the Socrative group which supported the results of Lee and Oh (2014). This confirmed the importance of employing this new mobile application in the pre-reading stage. When Socrative was implemented in the pre-reading stage, some significant pre-reading strategies such as predicting the content by reading the titles or subtitles, and providing pre-viewing questions to discuss before the main reading, were also incorporated. Particularly in the pre-reading stage, a class discussion about background knowledge (Stanovich, 2000) was a key component of the activity since pre-reading is often considered a vital step to understanding the main passage in the reading process (Hudson, 2007; Wilson \& Rupley, 1997). Therefore, active participation from students became one of the main issues for this study. Unfortunately, engaging students in a discussion was challenging in that few or even none of them volunteered to speak up in front of others. Thus, when Socraive was introduced and used for a class discussion, students positively and actively interacted with one another as confirmed in other studies (Green, 2016; Kaya \& Balta, 2016; Shaban, 2017; Wash, 2014). They created an active learning environment which promoted motivation (Agbatogun, 2014; Dakka, 2015; Hung, 2017). Moreover, students were able to learn the content of the reading passage unconsciously just by carrying out the activity. As a result, performing Socrative in the pre-reading stage might be an effective way to gather background knowledge and figure out the gist of the reading passage.

Another issue to be addressed is that using Socrative could bring many more learning benefits for students. Kay and LeSage (2009) identified five learning benefits including interaction, discussion, contingent teaching (modification of feedback from students), 
learning performance, and quality of learning (understanding key concepts). Based on the findings of the questionnaire and interview, the participants experienced all those five learning benefits (Kay \& LeSage, 2009) using Socrative. The most essential benefit may have been students' active engagement (Cardoso, 2011; Lee \& Oh, 2014; Yoon, 2017). They found it very interesting and motivating, enabling them to concentrate more on the class. Also, sharing their responses with other friends was delightful, and interaction with others provided them with knowledge and insights. For those who were introverted, Socrative offered the opportunity to express their opinions freely and confidently. Additionally, it could be assumed from the results of the questionnaire that anonymity was the key factor in making Socrative so attractive to students. On the other hand, one of the major barriers of SRS activities in this study was making unrelated comments. One student stated in the questionnaire that anonymity was an advantage as well as a disadvantage of using an SRS. Due to anonymity, as previously mentioned, students could express their thoughts without any concern of disclosing their identity. However, because their identity was protected, they could comment on anything, in any way, even though the remarks were completely out of the context. There is a good chance that those comments could hinder the development of a great learning environment if they are left to multiply without restriction. Accordingly, it is a pivotal responsibility of the instructor to make sure students focus on the learning content. With regard to English reading classes, because of the anonymity, students could become active learners by discussing the content of the passage through Socrative, reading others' opinions to resolve their misinterpretations, and checking their own understanding using the application's games and quizzes.

Lastly, the final question of the questionnaire was how to implement Socrative in the reading classes. Not many students volunteered to respond to this question, but interviewees had excellent suggestions which could be applied not only to pre-reading activities, but also to while- and post-reading activities. Applying these suggestions could enrich EFL students' learning experience.

Some limitations and suggestions for future studies are suggested. Due to the scope of the study, the present study was not able to carry out the experiment for a longer period of time since the pre-reading stage was a strict limit. In the future, with careful design of the experiment, longer hours with frequent usage may provide better insights for implementing Socrative. Moreover, the sample size may have been too small to be generalized. Further research could incorporate different proficiency levels and some other various groups with large classes. Finally, it is recommended that there should be more research to investigate the effects of different types of SRSs and how they could be integrated into all three reading stages. 


\section{REFERENCES}

Agbatogun, A. O. (2014). Developing learners' second language communicative competence through active learning: Clickers or communicative approach? Educational Technology \& Society, 17(2), 257-269.

Alemi, M., \& Ebadi, S. (2010). The effects of pre-reading activities on ESP reading comprehension. Journal of Language Teaching and Research, 1(5), 569-577.

Awedh, M., Mueen, A., Zafar, B., \& Manzoor, U. (2014). Using Socrative and smartphones for the support of collaborative learning. International Journal on Integrating Technology in Education, 3(4), 17-24.

Berry, L. (2015). Learner receptiveness towards mobile technology in a college English program. English Teaching, 70(1), 3-28.

Caldwell, J. E. (2007). Clickers in the large classroom: Current research and best-practice tips. Life Sciences Education, 6(1), 9-20.

Cardoso, W. (2011). Learning a foreign language with a learner response system: The students' perspective. Computer Assisted Language Learning, 24(5), 393-417.

Cha, Y. J., \& Kim, H. S. (2016). An alternative method for vocabulary learning using Quizlet. STEM Journal, 17(1), 117-144.

Chen, H. C., \& Graves, M. (1995). Effects of previewing and providing background knowledge on Taiwanese college students' comprehension of American short stories. TESOL Quarterly, 29(4), 663-686.

Chien, Y. T., Chang, Y. H., \& Chang, C. Y. (2016). Do we click in the right way? A metaanalytic review of clicker-integrated instruction. Educational Research Review, 17, 1-18.

Dakka, S. M. (2015). Using socrative to enhance in-class student engagement and collaboration. International Journal on Integrating Technology in Education, 4(3), 13-19.

Douglas, N., \& Bohlke, D. (2015). Reading explorer 3 (2 $2^{\text {nd }}$ ed.). Boston, MA: National Geographic Learning and Cengage Learning.

Fies, C., \& Marshall, J. (2006). Classroom response systems: A review of the literature. Journal of Science Education and Technology, 15(1), 101-109.

Grabe, W. (2009). Reading in a second language: Moving from theory to practice. New York, NY: Cambridge University Press.

Green, A. (2016). Significant returns in engagement and performance with a free teaching app. The Journal of Economic Education, 47(1), 1-10.

Han, H. J., \& Im, B. B. (2010). The effects of pre-reading activities on high school students' reading comprehension abilities in English. Modern English Education, 11(3), $162-189$ 
Hsu, L. (2013). English as foreign language learners' perception of mobile assisted language learning: A cross-national study. Computer Assisted Language Learning, 26(3), 197-213.

Hudson, R. (2007). Teaching second language reading. Oxford: Oxford University Press.

Hung, H. T. (2017). The integration of a student response system in flipped classrooms. Language Learning \& Technology, 21(1), 16-27.

Hunsu, N. J., Adesope, O., \& Bayly, D. J. (2016). A meta-analysis of the effects of audience response systems (cliker-based technologies) on cognition and affect. Computers \& Education, 94, 102-119.

Jang, E. J., \& Kim, J. Y. (2015). Uses of smartphone apps for English listening practice. Studies in English Education, 20(1), 27-53.

Jin, S. H. (2014). Implementation of smartphone-based blended learning in an EFL undergraduate grammar course. Multimedia-Assisted Language Learning, 17(4), 11-37.

Kay, R. H., \& LeSage, A. (2009). Examining the benefits and challenges of using audience response systems: A review of the literature. Computers and Education, 53(3), 819-827.

Kaya, A., \& Balta, N. (2016). Taking advantages of technologies: Using the socrative in English language teaching classes. International Journal of Social Sciences \& Educational Studies, 2(3), 4-12.

Kim, D., Rueckert, D., Kim, D.-J., \& Seo, D. (2013). Students' perceptions and experiences of mobile learning. Language Learning \& Technology, 17(3), 52-73.

Kim, H. J., \& Hur, K. (2016). A comparative study of the effects of implementing three different smartphones applications for English classes at a cyber university, with special reference to the students' affective domains and learning attainment. Multimedia-Assisted Language Learning, 19(1), 86-113.

Kim, H. S. (2014). Effects of using mobile devices in blended learning for English reading comprehension. Multimedia-Assisted Language Learning, 17(2), 64-85.

Kim, H. S., \& Cha, Y. J. (2017). A comparative study of pre-reading activities on university students' reading comprehension: Learning vocabulary vs. watching YouTube. Multimedia-Assisted Language Learning, 20(1), 11-34.

Kim, K. O., \& Park, S. H. (2015). The effects of process-based writing through the use of mobile SNS software on elementary English education. Multimedia-Assisted Language Learning, 18(1), 11-32.

Kim, N.-Y. (2018). Effects of reading aloud tasks through a mobile phone on EFL vocabulary and reading comprehension skills. Multimedia-Assisted Language Learning, 21(1), 57-76. 
Lee, C. M., \& Oh, E. J. (2014). Exploring the effects of a learner response system on EFL reading. Multimedia-Assisted Language Learning, 17(2), 130-151.

Lin, Y. C., Liu, T, C., \& Chu, C. C. (2011). Implementing clickers to assist learning in science lectures: The clicker-assisted conceptual change model. Australasian Journal of Educational Technology, 27(6), 979-996.

Liu, P. L. (2016). Mobile English vocabulary learning based on concept mapping strategy. Language Learning \& Technology, 20(1), 128-140.

McDonough, K., \& Foote, J. A. (2015). The impact of individual and shared clicker use on students' collaborative learning. Computers \& Education, 86, 236-249.

Moghaddam, N. N., \& Mahmoudi, A. (2016). The effects of pre-reading activities on reading comprehension of Iranian EFL learners. Advances in Language and Literacy Studies, 7(3), 235-242.

Moon, E. J., \& Kim, J. K. (2011). Effects of web-based and mobile bloggings on Korean college students' writing. Multimedia-Assisted Language Learning, 14(3), 224243.

O, K.-M. (2015). The effectiveness of mobile assisted language learning on L2 listening comprehension. Multimedia-Assisted Language Learning, 18(2), 135-158.

Patterson, B., Kilpatrick, J., \& Woebkenberg, E. (2010). Evidence for teaching practice: The impact of clickers in a large classroom environment. Nurse Education Today, 30(7), 603-607.

Pegrum, M. (2014). Mobile learning: Languages, literacies, and cultures. London: Palgrave Macmillan.

Penuel, W. R., Boscardin, C. K., Masyn, K., \& Crawford, V. M. (2007). Teaching with student response systems in elementary and secondary education settings: A survey study. Education Technology Research and Development, 55(4), 315-346.

Praag, B. V., \& Sanchez, H. S. (2015). Mobile technology in second language classrooms: Insights into its uses, pedagogical implications, and teacher beliefs. ReCALL, 27(3), 288-303.

Puentedura, R. R. (2014). SAMR: First steps [Presentation slides]. Retrieved from http://www.hippasus.com/rrpweblog/archives/2014/11/13/SAMR_FirstSteps.pdf

Richards, J. C. (2015). Key issues in language teaching. Cambridge, UK: Cambridge University Press.

Shaban, A. E. (2017). The use of Socrative in ESL classrooms: Towards active learning. Teaching English With Technology, 17(4), 64-77.

Socrative [Mobile application software]. (2017). Retrieved from http://www.socrative. com

Stanovich, K. (2000). Progress in understanding reading: Scientific foundation and new frontiers. New York, NY: Guilford Press. 
Stav, J., Nielsen, K., Hansen-Nygard, G., \& Thorseth, T. (2010). Experiences obtained with integration of student response systems for iPod Touch and iPhone into elearning environments. The Electronic Journal of e-Learning, 8(2), 179-190.

Stockwell, G. (2010). Using mobile phones for vocabulary learning activities: Examining the effect of the platform. Language Learning \& Technology, 14(2), 95-110.

Stowell, J. R., \& Nelson, J. M. (2007). Benefits of electronic audience response systems on student participation, learning and emotion. Teaching of Psychology, 34(4), 253-258.

Wang, A. I. (2015). The wear out effect of a game-based student response system. Computers \& Education, 82, 217-227.

Wang, S., \& Smith, S. (2013). Reading and grammar learning through mobile phones. Language Learning \& Technology, 17(3), 117-134.

Wash, P. D. (2014). Taking advantage of mobile devices: Using Socrative in the classroom. Journal of Teaching and Learning With Technology, 3(1), 99-101.

Waters, S., Kenna, J., \& Bruce, D. (2016). Apps-olutely perfect! Apps to support common core in the history/social studies classroom. The Social Studies, 107(3), 1-7.

Wilson, V. L., \& Rupley, W. H. (1997). A structural equation model for reading comprehension based on background, phonemic, and strategy knowledge. Scientific Studies of Reading, 1, 45-63.

Yoon, S. Y. (2017). Using learner response systems in EFL classrooms: Students' perspectives and experience. Multimedia-Assisted Language Learning, 20(2), 3658.

APPENDIX

Students' Responses on Screen

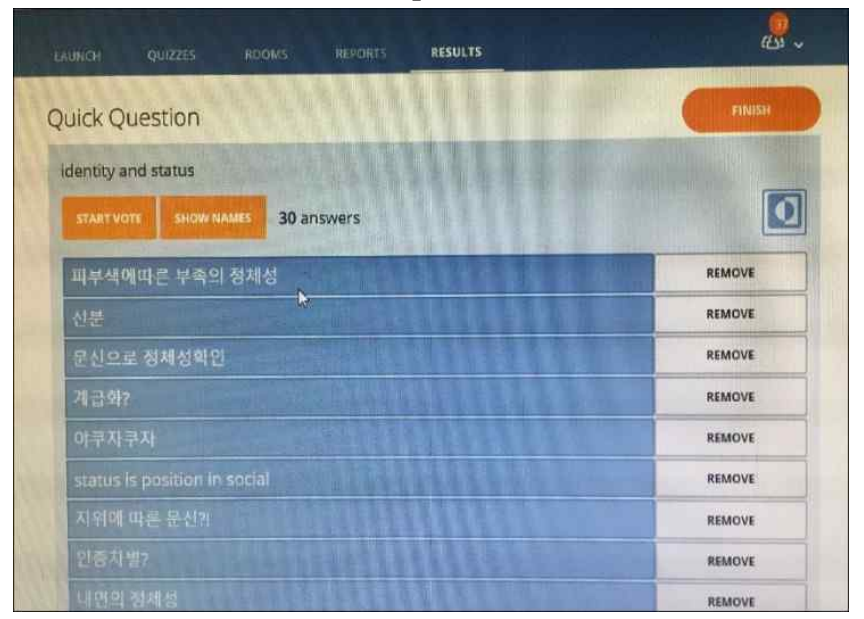


Applicable level: tertiary

Keywords: SRS (student response system), Socrative, learner perspectives, pre-reading stage

Cha, Yoonjung

Department of King Jeongjo College of Liberal Arts

Hanshin University

137 Hanshindae-Gil, Osan-Si, Gyeonggi-Do, 18101

E-mail: yjcha@hs.ac.kr

Received: April 15, 2018

Revised version: May 15, 2018

Accepted: May 26, 2018 